\title{
Phase transformations in nanocomposite ZrAIN thin films during annealing
}

Lina Rogström, Mats Ahlgren, J. Almer, Lars Hultman and Magnus Odén

\section{Linköping University Post Print}

N.B.: When citing this work, cite the original article.

Original Publication:

Lina Rogström, Mats Ahlgren, J. Almer, Lars Hultman and Magnus Odén, Phase transformations in nanocomposite ZrAlN thin films during annealing, 2012, Journal of Materials Research, (27), 13, 1716-1724.

http://dx.doi.org/10.1557/jmr.2012.122

Copyright: Cambridge University Press (CUP) / Materials Research Society http://www.mrs.org/

Postprint available at: Linköping University Electronic Press http://urn.kb.se/resolve?urn=urn:nbn:se:liu:diva-75171 


\title{
Phase transformations in nanocomposite ZrAIN thin films during annealing
}

\author{
Lina Rogström ${ }^{\text {a) }}$ \\ Nanostructured Materials, Department of Physics, Chemistry, and Biology (IFM), Linköping University, \\ S-581 83 Linköping, Sweden \\ Mats Ahlgren \\ Sandvik Tooling AB, 12680 Stockholm, Sweden \\ Jonathan Almer \\ Advanced Photon Source, Argonne National Laboratory, Argonne, Illinois 60439 \\ Lars Hultman \\ Thin Film Physics, Department of Physics, Chemistry, and Biology (IFM), Linköping University, \\ S-581 83 Linköping, Sweden \\ Magnus Odén \\ Nanostructured Materials, Department of Physics, Chemistry, and Biology (IFM), Linköping University, \\ S-581 83 Linköping, Sweden
}

(Received 23 November 2011; accepted 16 March 2012)

\begin{abstract}
Nanocomposite $\mathrm{Zr}_{0.52} \mathrm{Al}_{0.48} \mathrm{~N}_{1.11}$ thin films consisting of crystalline grains surrounded by an amorphous matrix were deposited using cathodic arc evaporation. The structure evolution after annealing of the films was studied using high-energy x-ray scattering and transmission electron microscopy. The mechanical properties were characterized by nanoindentation on as-deposited and annealed films. After annealing in temperatures of $1050-1400{ }^{\circ} \mathrm{C}$, nucleation and grain growth of cubic $\mathrm{ZrN}$ takes place in the film. This increases the hardness, which reaches a maximum, while parts of the film remain amorphous. Grain growth of the hexagonal AlN phase occurs above $1300{ }^{\circ} \mathrm{C}$.
\end{abstract}

\section{INTRODUCTION}

Nanocomposite films consisting of one amorphous phase and one or more nanocrystalline phases can exhibit very high hardness. This has been explained by hindering of dislocation motion by the thin amorphous matrix surrounding the crystallites. ${ }^{1}$ Hard nanocomposites of several material systems have been studied, e.g., Ti-Si-N, ${ }^{1,2}$ Ti-Si-C-N, ${ }^{3,4} \mathrm{Zr}-\mathrm{Si}-\mathrm{N},{ }^{5}$ and Ti-B-N. ${ }^{6,7}$ Such nanocomposites also retain their hardness at high temperatures since the grain growth is hindered by the amorphous matrix. ${ }^{8}$ Also two-phase nanocrystalline materials in the form of multilayers exhibit an increased hardness compared to their constituents due to the difference in elastic properties between the layers that hinder dislocation motion, ${ }^{9}$ most clearly seen in nanoscale multilayers. ${ }^{10,11}$

The decomposition of metastable single-phase films can also act to improve the hardness at elevated temperature as a two-phase structure is formed. The most studied of these is the TiAlN system where age hardening upon annealing of thin films was first observed. ${ }^{12,13}$ In the TiAlN system, the metastable cubic solid solution undergoes spinodal

\footnotetext{
a) Address all correspondence to this author.

e-mail: linro@ifm.liu.se

DOI: $10.1557 / \mathrm{jmr} .2012 .122$
}

decomposition during annealing into cubic domains enriched in TiN and AlN. ${ }^{14}$ The generated coherency strains between the domains and the difference in elastic properties between domains of different $\mathrm{Al}$ content ${ }^{15}$ hinder dislocation motion and thus increase the hardness. Following this example, age hardening during annealing has been observed for solid solution films of TiAlSiN, ${ }^{16}$ TiSiCN,${ }^{17} \mathrm{TiBN}^{18}$ and TiAlCrN. ${ }^{19}$

The large miscibility gap of the $\mathrm{ZrN}-\mathrm{AlN}$ system makes deposition of a solid solution possible only for low $\mathrm{Al}$ contents. ${ }^{20-23} \mathrm{AlN}$ contents higher than 50 at.\% result in a film consisting of cubic, hexagonal, and amorphous parts. During annealing, these nanocomposite films decompose into the equilibrium phase cubic (c)- $\mathrm{ZrN}$ and hexagonal (h)-AlN. ${ }^{22,23}$ This yielded improved mechanical properties of the $\mathrm{ZrAlN}$ thin films due to the enhanced crystal quality and the microstructure formed during decomposition. ${ }^{22}$ However, the structural evolution during annealing of nanocomposite ZrAlN thin films is not well understood. In this study, we use high-energy x-ray scattering techniques to follow the phase transformation and structural evolution of nanocomposite ZrAlN thin films as a function of annealing temperature. The observed structural evolution helps to explain the mechanical properties of the film. 


\section{EXPERIMENTAL DETAILS}

Thin ZrAlN films were deposited using an Oerlikon Balzers RCS arc evaporation system (Oerlikon Balzers, Balzers, Liechtenstein). Two cathodes with a $\mathrm{Zr:Al}$ ratio of 50:50 were placed in a vertical row in the deposition chamber. Substrates of polished WC-Co were mounted facing the cathodes and were kept still during deposition. The depositions were performed in a $\mathrm{N}_{2}$ reactive gas environment, with a pressure of $2.5 \mathrm{~Pa}$. A negative bias of $40 \mathrm{~V}$ was applied to the substrates. The temperature during deposition was approximately $250{ }^{\circ} \mathrm{C}$ and the deposition rate was $\sim 380 \mathrm{~nm} / \mathrm{min}$.

The composition of the as-deposited film was determined by elastic recoil detection analysis (ERDA) using a $40 \mathrm{MeV} \mathrm{I}^{+}$beam. A fractured cross section was studied in a LEO 1550 FEG scanning electron microscope (SEM; Zeiss, Oberkochen, Germany). Polished and ion-milled cross-sectional samples of as-deposited and annealed films were studied in a FEI Technai G2 transmission electron microscope (FEI, Hillsboro, OR) using an acceleration voltage of $200 \mathrm{kV}$. Selected area electron diffraction (SAED) patterns were taken from an area with a diameter of $0.8 \mu \mathrm{m}$.

After deposition, samples were cut into $1 \pm 0.01 \mathrm{~mm}$ thick slices and heat treated to different maximum temperatures. The heat treatments were performed in a He atmosphere with a heating rate of $20 \mathrm{~K} / \mathrm{min}$. The samples were heated up to the maximum temperature and then cooled with $20 \mathrm{~K} / \mathrm{min}$ with no holding time at the maximum temperature.

Nanoindentation on as-deposited and annealed samples was performed on polished tapered cross sections using a UMIS 2000 system (Fisher-Cripps Laboratories, Forestville, Australia) and a maximum indentation depth of $300 \mathrm{~nm}$. The data were analyzed using the method of Oliver and Pharr ${ }^{24}$ and reference measurements were performed in fused silica.

As-deposited and heat-treated samples were analyzed at beamline 1-ID at the Advanced Photon Source at Argonne National Lab using high-energy x-ray radiation with a wave length of $\lambda=0.1907 \AA$. The samples were placed with the film in the $10 \times 10 \mu \mathrm{m}^{2}$ beam with the growth direction (GD) vertical to the beam as schematically shown in Fig. 1. A two-dimensional detector (GE Angio, Billerica, MA) was placed at $1304 \mathrm{~mm}$ from the sample for detection of wide angle scattered (WAXS) diffracted intensity. A second two-dimensional detector (PI CCD; Princeton Instruments, Trenton, NJ) was placed at a distance of $4050 \mathrm{~mm}$ from the sample to detect the small angle scattering (SAXS). The sample-to-detector distance was calibrated using $\mathrm{CeO}$ powder. The WAXS exposures consisted of 10 summed 2-s snap shots and the SAXS exposures were taken for $20 \mathrm{~s}$.

The two-dimensional WAXS diffraction patterns were transformed into $5^{\circ}$-wide azimuthal bins resulting in 72 one-dimensional line-outs. A pseudo-Voigt function was fitted to the diffraction peaks for each lineout to extract the

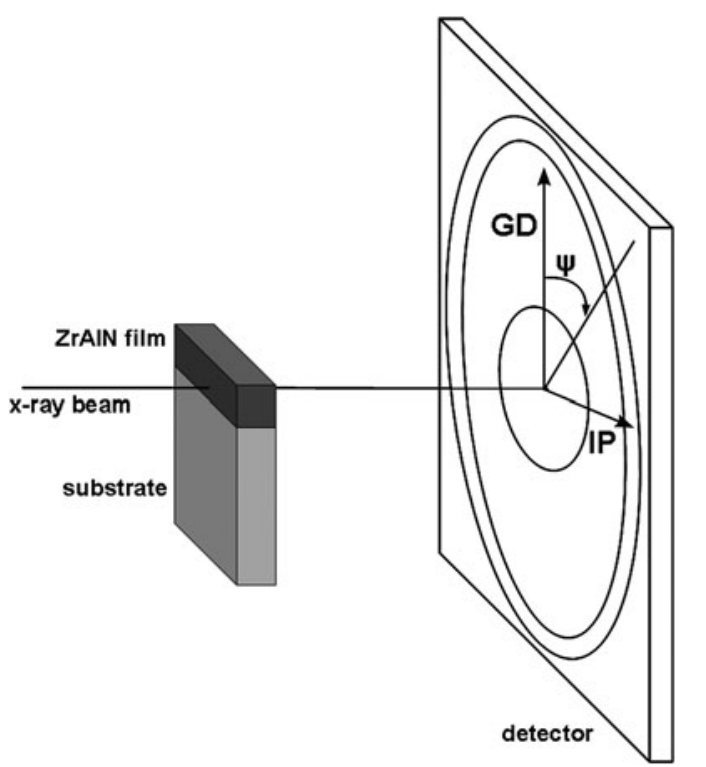

FIG. 1. Schematic of the setup during x-ray scattering experiments. The tilt angle, $\psi$, and the film in-plane (IP) and growth (GD) direction are shown.

plane spacing $(d)$, the integrated intensity, and the integral breadth $(\Delta 2 \theta)$.

The general contributions to peak broadening are

$$
\Delta 2 \theta \cos \theta=\left(\frac{\lambda}{D}\right)+2\left\langle\left(\frac{\Delta d}{d}\right)^{2}\right\rangle^{1 / 2} \sin \theta,
$$

where $\left\langle\left(\frac{\Delta d}{d}\right)^{2}\right\rangle^{1 / 2}$ is the average microstrain and $D$ is the crystallite size. The measured peak broadening is corrected for instrumental contribution where the integral breadth of the substrate peaks is used as a measure of the instrumental broadening. The contributions from size and microstrain to the peak broadening, $\Delta 2 \theta$, are separated by plotting the peak broadening as a function of $\sin (\theta)$. The $\mathrm{ZrN} \mathrm{111,} \mathrm{200,} \mathrm{220,} \mathrm{311,} \mathrm{and} 222$ reflections are used and a linear function is fitted to the data. The two contributions are then separated by use of Eq. (1).

The average macrostrain in the film measured from the 200 reflection in the in-plane (IP), $\psi=\left[80: 100^{\circ}\right]$, and $\mathrm{GD}, \psi=\left[-10: 10^{\circ}\right]$, is determined as $\varepsilon_{\psi}=\left(d_{\psi}-d_{0}\right) / d_{0}$, where $d_{0}$ is the unstrained lattice parameter. $d_{0}$ was determined at a tilt angle of $\psi=30^{\circ}$, which is the orientation in these coatings where the lattice spacing is invariant as a function of internal strain. The invariant tilt angle is calculated through the Reuss model ${ }^{25}$ using single crystal elastic compliances $\left(S_{11}=1.73, S_{12}=-0.243\right.$, and $S_{44}=7.8091 / \mathrm{TPa}$ ) determined by ab initio calculations. ${ }^{26}$

The SAXS data were corrected for detector dark current and background scattering, e.g., air scattering. Transformation to one-dimensional line-outs at $\psi=45^{\circ}$ was performed using $6^{\circ}$-wide azimuthal bins. The line-outs 
were then fitted to a size distribution function using the maximum entropy method ${ }^{27}$ in the IRENA package for $\mathrm{IGOR}^{28}$ assuming spherical particles. The scattering contrast was estimated using the scattering contrast calculator in the IRENA package. The scattering species can be grains of $c$-ZrN, $c$-AlN, or $h$-AlN or amorphous domains with a different chemical composition than that of the matrix, why a mean value for the scattering contrast $\left[(\Delta \rho)^{2}=100 \times 10^{20} \mathrm{~cm}^{-4}\right]$ was used. Since the value only changes the calculated volume of scattering particles, it is still possible to make qualitative comparisons of the size distributions. From the size distributions, the number of scattering particles and the mean particle diameter was extracted between 40 and $260 \AA$, where $40 \AA$ corresponds to the smallest detectable particle size.

\section{RESULTS}

The composition of the as-deposited film determined by ERDA is $\mathrm{Zr}_{0.52} \mathrm{Al}_{0.48} \mathrm{~N}_{1.11}$. The thickness of the film is $7.5 \mu \mathrm{m}$ as determined from fractured cross sections studied in the SEM. The appearance of the film is glassy and no columnar structure can be observed (not shown).

Figure 2(a) shows an elemental contrast scanning transmission electron micrograph (STEM) micrograph from the as-deposited film. Contrast from compositional variations can be seen in the micrograph with $\mathrm{ZrN}$ - and AlN-rich features that are 1-2 $\mathrm{nm}$ in diameter. Some of the bright contrast AlN-rich features are marked with black arrows in the figure. In the high-resolution transmission electron micrograph (TEM) micrograph, Fig. 2(b), small crystalline grains are observed with a size of the order of 2-5 $\mathrm{nm}$. Between the grains, the structure is amorphous. The corresponding SAED pattern shows broad and diffuse diffraction rings. The diffraction rings can be assigned to a mixture of one cubic and one hexagonal phase.

Figure 3(a) shows an elemental contrast STEM micrograph of the film after annealing at $1250{ }^{\circ} \mathrm{C}$. A stronger contrast is observed and the $\mathrm{ZrN}$ - and $\mathrm{AlN}$-rich domains are larger in this case compared to the as-deposited film. In the high-resolution micrograph of the annealed film, Fig. 3(b), a larger part of the film is crystalline and the grains are larger than in the as-deposited case. The diffraction rings in the SAED pattern are better defined in this case and the rings with high intensity belong to a cubic structure. Low intensity diffraction rings from a hexagonal structure can also be observed.

Figure 4 shows one-dimensional WAXS line-outs in the IP direction, $\psi=\left[80: 100^{\circ}\right]$, of the as-deposited and annealed films. The diffractogram of the as-deposited film shows no diffraction peaks other than those arising from the substrate. The small peaks centered at $d=1.79 \AA$ and $d=2.40 \AA$ visible in some of the line-outs origin from $\mathrm{ZrAl}$ intermetallic macroparticles in the films. ${ }^{29,30}$ After annealing at $1150{ }^{\circ} \mathrm{C}$, small diffraction peaks from $c-\mathrm{ZrN}$

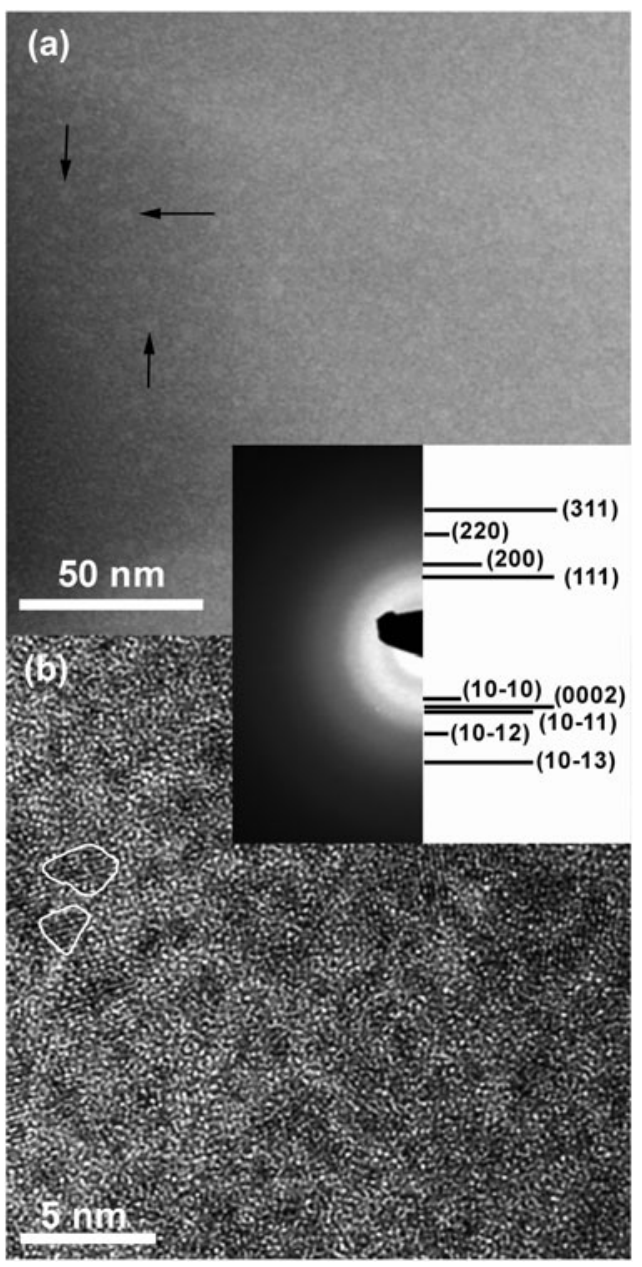

FIG. 2. (a) STEM and (b) high-resolution TEM micrographs with selected area electron diffraction pattern as inset of the as-deposited film. The arrows in (a) point at AlN-rich domains and the white lines in (b) show the outline of two grains.

and $h$-AlN can be observed. Between 1200 and $1300{ }^{\circ} \mathrm{C}$, the intensity of the $c$ - ZrN diffraction peaks increases, while the peaks from $h$-AlN remain small. Annealing at $1400{ }^{\circ} \mathrm{C}$ causes the $c$ - $\mathrm{ZrN}$ peaks to narrow and increase in intensity and also the intensity of peaks from the $h$-AlN phase increase.

Figure 5(a) shows the integrated IP intensity of the $c$ - $\mathrm{ZrN}$ (200) diffraction peak as a function of annealing temperature. The intensity increases slightly for annealing temperatures between 1050 and $1250{ }^{\circ} \mathrm{C}$. After annealing at temperatures higher than $1250^{\circ} \mathrm{C}$, the increase is greater. A similar increase is observed in the film GD (not shown). Figure 5(b) shows the microstrain and crystallite size determined from the broadening of the $c$ - $\mathrm{ZrN}$ diffraction peaks. Between 1100 and $1250^{\circ} \mathrm{C}$, the crystallite size decreases, while the microstrain increases. Between 1300 and $1400{ }^{\circ} \mathrm{C}$, the reverse trend is observed.

Figure 6 shows the IP macrostrain for $c-\mathrm{ZrN}$ and WC phases as a function of temperature. The $c-\mathrm{ZrN}$ strain is small, tensile, and does not change significantly with 


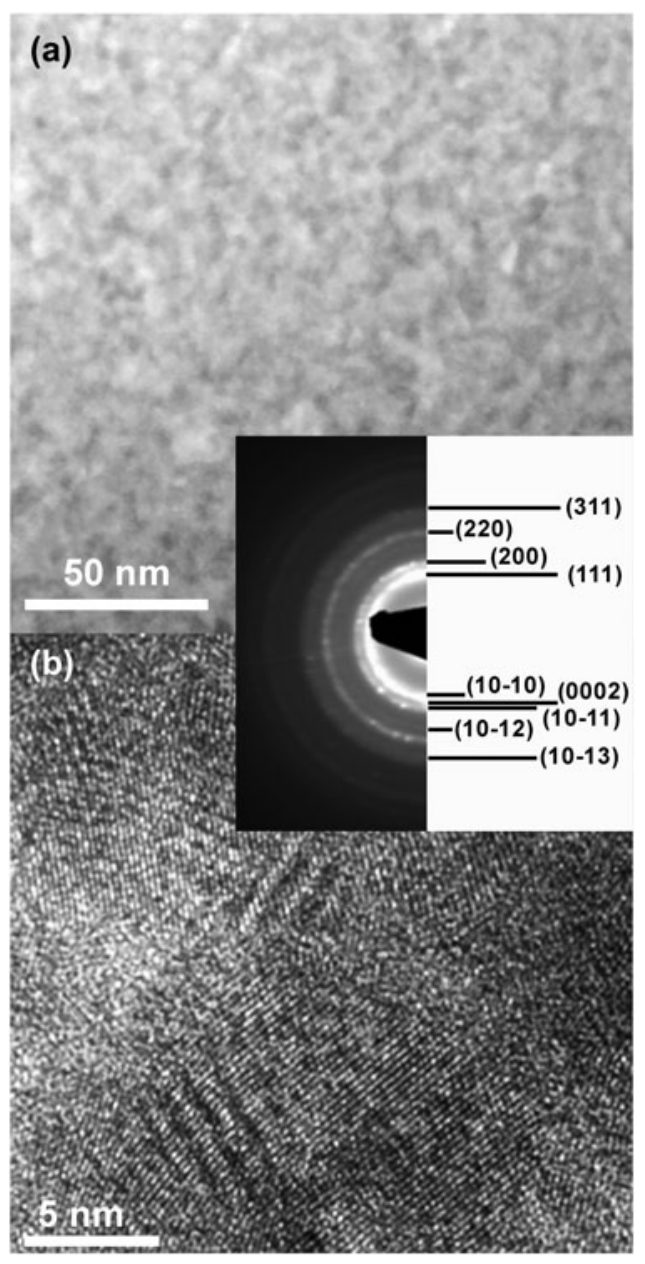

FIG. 3. (a) STEM micrograph of the ZrAlN film annealed at $1250{ }^{\circ} \mathrm{C}$; and (b) high-resolution TEM micrograph with selected area electron diffraction pattern inset of the same sample.

temperature. The strain in the WC substrate is close to zero at all temperatures, with a slight tensile component after the highest temperature anneal.

Figure 7 shows the detected SAXS signal for three annealing temperatures. The cross-shaped feature in the middle is the beam stop. Observed are also vertical streaks arising from scattering at the beam-defining slits. With increasing annealing temperature, the intensity of the SAXS pattern increases. After annealing at $1400{ }^{\circ} \mathrm{C}$, the scattered intensity decreases at large angles and becomes higher at small angles due to an increased particle size.

Figures 8(a) and 8(b) show the SAXS-derived particle size distribution and the extracted mean diameter and number of scattering particles, respectively. For annealing temperatures lower than $1150{ }^{\circ} \mathrm{C}$, there is not enough scattered intensity to extract qualitative data. Between 1150 and $1250{ }^{\circ} \mathrm{C}$, the maximum number of scattering particles is found around a diameter of $60 \AA$. Inserted in Fig. 8(a) is also a zoomed-in part of the size distribution for three temperature steps showing a second peak in the size

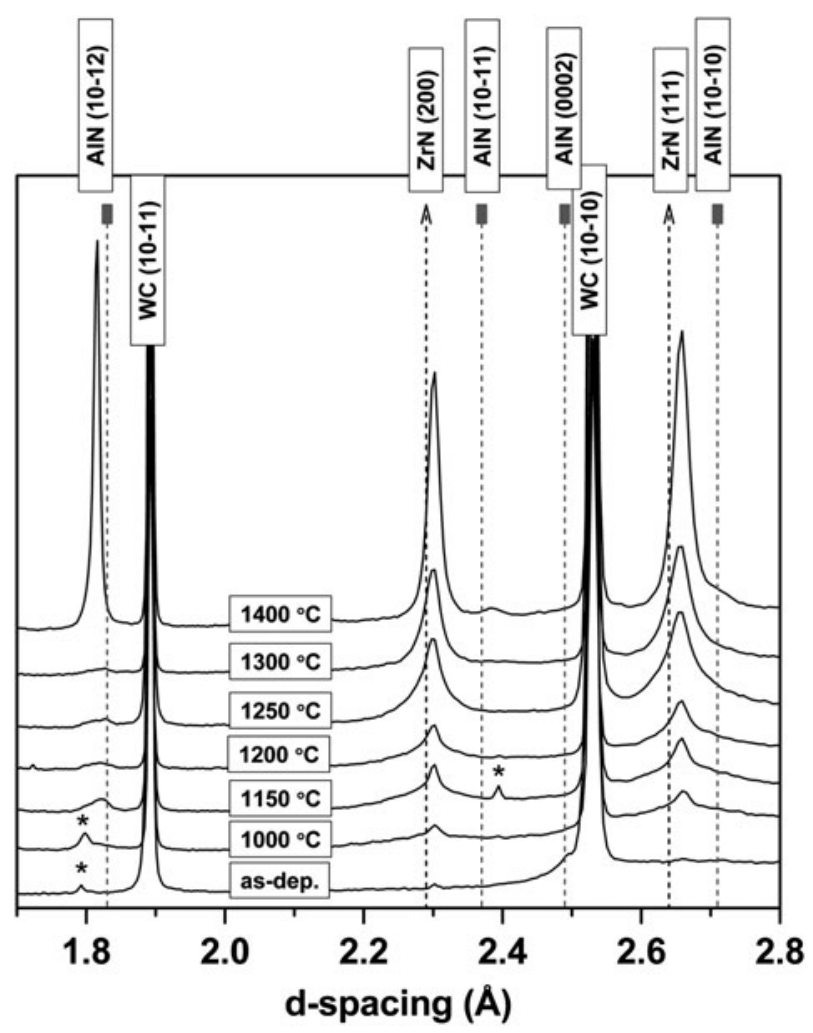

FIG. 4. Wide angle scattering line-outs in the film in-plane direction of the as-deposited and annealed films. Peaks labeled with * arises from $\mathrm{ZrAl}$ intermetallic macroparticles in the films.

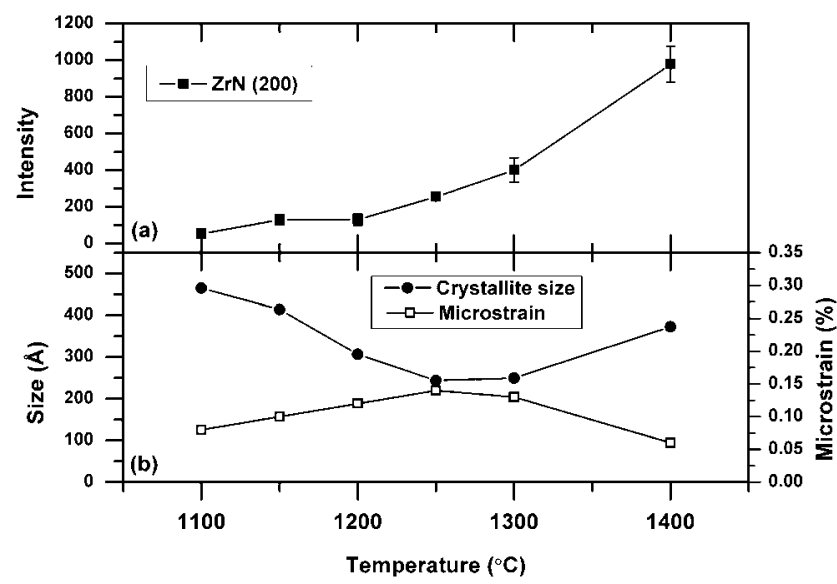

FIG. 5. (a) in-plane intensity and (b) crystallite size and microstrain derived from the $c-\mathrm{ZrN} 200$ peak.

distribution around a diameter of $\sim 200 \AA$. The size of this peak shows no changes with temperature below $1400{ }^{\circ} \mathrm{C}$. For all annealing temperatures, there is also a tail in the size distribution toward higher diameters and smaller peaks centered at $\sim 320$ and $\sim 430 \AA$. The number of scattering particles increases with temperature up to $1250{ }^{\circ} \mathrm{C}$ as can be seen in Fig. 8(b). At temperatures higher than 
$1250{ }^{\circ} \mathrm{C}$, the maximum number of scattering particles is shifted to larger diameters. At $1400^{\circ} \mathrm{C}$, the distribution is also wider and the increase of the second small peak around $200 \AA$ at this temperature is attributed to coalescence of smaller particles. In Fig. 8(b), the number of particles is observed to decrease for annealing temperatures above $1250{ }^{\circ} \mathrm{C}$. The particle mean diameter decreases between 1150 and $1200{ }^{\circ} \mathrm{C}$, increases at temperatures higher than $1250{ }^{\circ} \mathrm{C}$, and reaches a maximum value of $67 \AA$ after annealing at $1400{ }^{\circ} \mathrm{C}$.

Figure 9 shows the hardness and elastic modulus as a function of annealing temperature. Both the hardness and elastic modulus of the as-deposited film are rather low, compared to $\mathrm{ZrN}$, with $H=14.2 \mathrm{GPa}$ and $E=235 \mathrm{GPa}$. After annealing, the hardness and elastic modulus increase. The hardness reaches a maximum of $22.4 \mathrm{GPa}$ after annealing in $1250{ }^{\circ} \mathrm{C}$, while the elastic modulus increases to its maximum value of $348 \mathrm{GPa}$ at $1400{ }^{\circ} \mathrm{C}$.

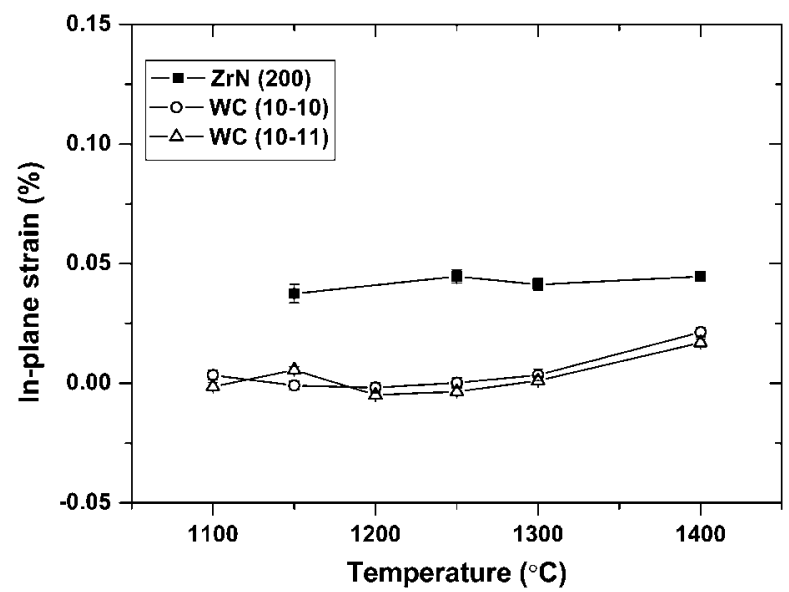

FIG. 6. In-plane strain for the $\mathrm{ZrN}$ (200) planes and WC (10-10) and (10-11).

\section{DISCUSSION}

\section{A. Structure of the as-deposited film}

The as-deposited $\mathrm{Zr}_{0.52} \mathrm{Al}_{0.48} \mathrm{~N}_{1.11}$ film has a nanocomposite structure with small grains surrounded by an coalescence or disordered matrix, see Fig. 2(b). As observed from the STEM micrograph, Fig. 2(a), some separation into $\mathrm{ZrN}$ - and AlN-rich domains has taken place already during deposition. No previous studies report a solid solution structure for such a high $\mathrm{Al}$ content for the $\mathrm{ZrAlN}$ system but a mixture of cubic, hexagonal, and/or amorphous regions has been observed. ${ }^{20-22}$ The broad diffraction rings in the SAED pattern, Fig. 2, can be assigned to a two-phase structure with small $c$ - $\mathrm{ZrN}$ and $h$-AlN grains, although the broadness makes the identification difficult. Deposition of two immiscible phases can result in hindered grain growth and causes renucleation during deposition, ${ }^{31}$ which is a strategy used to grow other nanocomposite films, see, e.g., Refs. 32-34.

In this study, the substrate holder was not rotated during deposition, wherefore the film is under constant ion flux during growth. This will increase the deposition rate and also the local temperature of the film during deposition ${ }^{35}$ compared to depositions with substrate holder rotation but otherwise similar parameters. ${ }^{22}$ Higher temperature would give the atoms in the growing film more energy for diffusion and thus higher possibility to find low-energy sites. In the present case, however, even smaller grains are observed compared to what was obtained in Ref. 22, which could be due to the larger amount of ion bombardment and higher deposition rate. The substrate bias is also lower here compared to earlier studies, ${ }^{22,23}$ which further limits the atom mobility.

The film has a nitrogen-to-metal ratio above one, which has previously been observed for nanocomposite ZrAlN thin films. ${ }^{22}$ This is likely a result from limited adatom mobility during growth, which causes formation of vacancies on the metal sublattice as has been observed

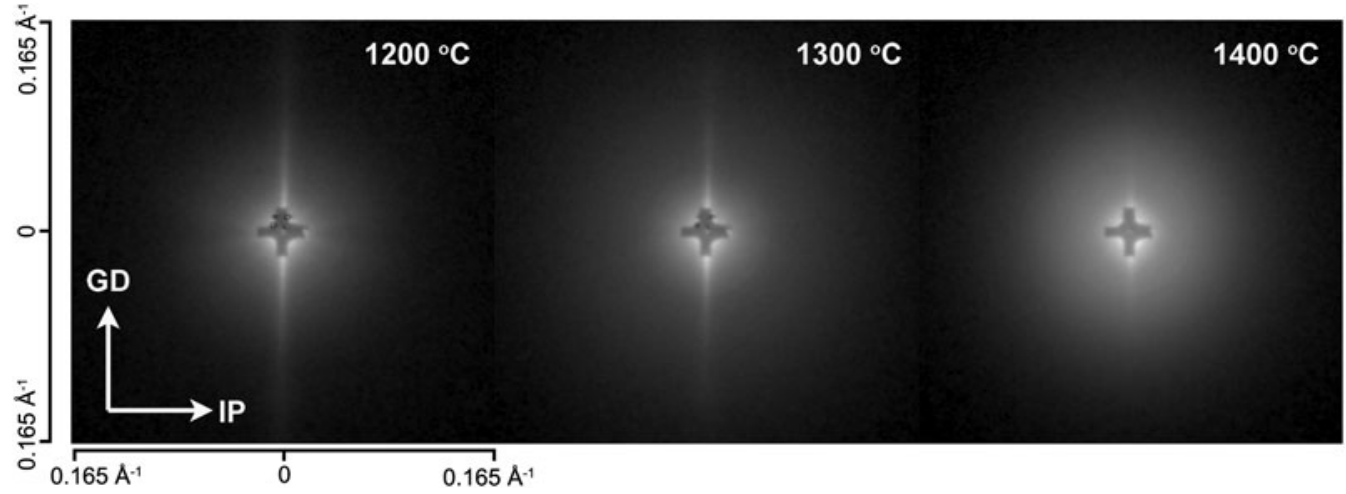

FIG. 7. Detected SAXS intensity at three temperature steps. The in-plane (IP) and growth direction (GD) are labeled. 
for $\mathrm{ZrN}$ thin films. ${ }^{36,37}$ The amorphous phase present in the ZrAlN films here might also be able to accommodate a high nitrogen content.

\section{B. Structure evolution during annealing}

Further separation into $\mathrm{ZrN}$ - and AlN-rich domains has taken place after annealing at $1150{ }^{\circ} \mathrm{C}$, as observed from the WAXS line-outs diffraction experiment in Fig. 4 and at $1250{ }^{\circ} \mathrm{C}$ as observed from the STEM micrograph in Fig. 3(a). The domains are larger than in the as-deposited state and the contrast between domains is higher. Differential scanning calorimetry (DSC) results for a similar film in Ref. 23 showed an exothermic reaction between the deposition temperature and $\sim 1050{ }^{\circ} \mathrm{C}$, which based on related TiAlN system was assigned to defect annihilation and crystal recovery. ${ }^{12,14}$ Thus, the separation of diffraction peaks from $c$ - $\mathrm{ZrN}$ and $h$-AlN at $1150{ }^{\circ} \mathrm{C}$ is assigned to growth and improved crystal quality of grains that may be present already in the as-deposited film.

The contrast in SAXS depends on differences in electron density within the material. These differences can arise due to differences in composition or crystal structure or due to voids or pores in the sample. As no voids are observed by TEM, the SAXS contrast arises from differences in composition and/or atomic arrangement. The contrast in STEM arises from differences in chemical composition and the observed size of the domains may be influenced by the projection of overlapping domains. The particle size as determined from SAXS can thus not be directly compared to the size of $\mathrm{ZrN}$ - and AlN-rich domains seen by STEM. The size of $\mathrm{ZrN}$ - and AlN-rich domains is, however, similar as seen by STEM, wherefore the SAXS-derived size distribution was used to qualitatively compare with diffraction data from the $c-\mathrm{ZrN}$ phase.

From the change of diffraction peak intensity of the $c$-ZrN phase in Fig. 5(a), two temperature regions during growth of $c-\mathrm{ZrN}$ can be discerned. Between 1100 and $1250{ }^{\circ} \mathrm{C}$, only a small change in intensity is observed, while the increase is greater above $1250{ }^{\circ} \mathrm{C}$.

In the first temperature region, between 1100 and $1250^{\circ} \mathrm{C}$, the number of scattering domains increases, see Fig. 8(b). The SAXS results also show a small decrease in mean particle diameter between 1150 and $1200^{\circ} \mathrm{C}$, see Fig. 8(b). This is due to the formation of particles with a smaller diameter that results in a broadening of the particle size distribution toward smaller dimensions, see Fig. 8(a). The crystallite size derived from the diffraction peak broadening [Fig. 5(b)] shows the same trend with decreasing crystallite size between 1100 and $1250^{\circ} \mathrm{C}$. There is a large difference between the mean diameter derived from SAXS and the crystallite size derived from the WAXS data. The mean diameter from the SAXS size distribution is a measure on the most commonly present diameter size in the sample. In the size distribution, it is observed that also particles with larger diameters are present. These particles are fewer but make up a relative large volume of the sample due to their size. The WAXS-derived average size is therefore largely influenced by the presence of these larger grains. Between 1250 and $1400{ }^{\circ} \mathrm{C}$, the intensity of the $c$-ZrN diffraction peaks increases significantly. The WAXS-derived crystallite size shows that the average size increases between 1300 and $1400{ }^{\circ} \mathrm{C}$, and the SAXS results show that the mean diameter is increased within this temperature interval. After annealing at $1400^{\circ} \mathrm{C}$, the number of larger particles has increased as seen in the insert in Fig. 8(b). The SAXS results further show that the number of scattering particles decreases for temperatures above $1250{ }^{\circ} \mathrm{C}$ suggesting that the existing grains coalesce and larger grains grow at the expense of the smaller grains.

The WAXS line-outs in Fig. 4 show that the intensity of $h$-AlN diffraction peaks remains constant below $1400^{\circ} \mathrm{C}$. Thus, during separation of $\mathrm{ZrN}$ and $\mathrm{AlN}, c-\mathrm{ZrN}$ nucleates and grows in the $\mathrm{ZrN}$-rich domains, while the structure of AlN-rich domains is still partly amorphous with only small $h$-AlN grains. The slower growth of $h$-AlN compared to $c$-ZrN during annealing of ZrAlN thin films was also observed in Refs. 22 and 23. $h$-AlN is a stoichiometric compound that can not dissolve nitrogen contents higher than 50 at.\%, thus, the high nitrogen content in the film can hinder formation of $h$-AlN. As observed from DSC/thermogravimetry (TG) results in Ref. 23, nitrogen is lost from the film at about the same temperature as the formation of $h$-AlN. $c-\mathrm{ZrN}_{x}$ is less sensitive for the nitrogen concentration and can form even with nitrogen contents higher than $x=1{ }^{38-40}$ Further, the $c-\mathrm{ZrN}$ phase can dissolve small amounts of $\mathrm{Al}$ and form a metastable $c$-ZrAlN phase. ${ }^{21,41,42}$ The observed $\mathrm{ZrN}$ phase can thus contain both a higher nitrogen content than 50 at.\% and possibly some Al.

The macrostrain in the $c-\mathrm{ZrN}$ phase is small for all temperatures. The $c-\mathrm{ZrN}$ formed can be expected to have a smaller molar volume than the amorphous matrix. A smaller molar volume of the cubic phase would cause tensile strains in this phase, which is also observed. In addition, thermal strains should appear due to difference in coefficient of thermal expansion (CTE) between the substrate, $c-\mathrm{ZrN}$, and the amorphous phase. The CTE of $c-\mathrm{ZrN}$ $\left[7.24 \times 10^{-6}{ }^{\circ} \mathrm{C}^{-1}\right.$ (Ref. 43)] is higher than that of the substrate $\left[\sim 5 \times 10^{-6}{ }^{\circ} \mathrm{C}^{-1}\right.$ (Ref. 44)]. As the measurements are performed at a temperature lower than the formation temperature of $c-\mathrm{ZrN}$, this would result in tensile stresses. The simultaneous effect of molar volume mismatch and thermal strains makes the two contributions not possible to separate in this case.

The microstrain changes with temperature and increases between 1100 and $1250{ }^{\circ} \mathrm{C}$, connected to the nucleation of new grains as seen by the decreased particle size derived from the SAXS and WAXS data. Compositional fluctuations within the new grains are most likely 

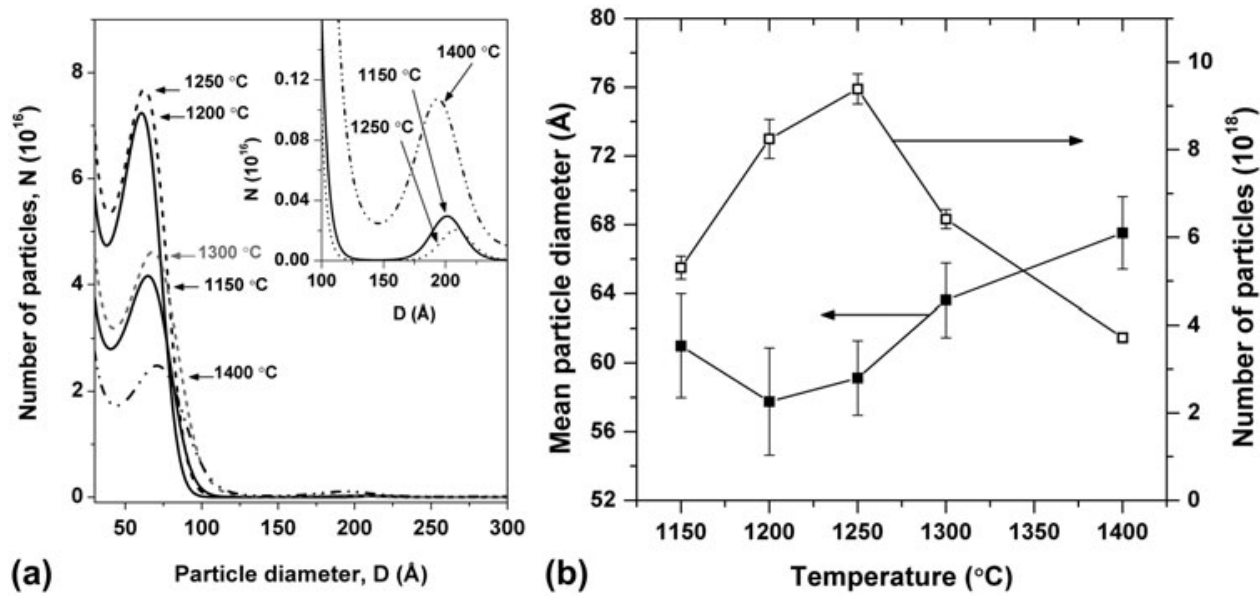

FIG. 8. (a) size distribution and (b) size (filled symbols) and number (open symbols) of scattering particles as a function of temperature. Inserted in (a) is a zoomed-in part around $175 \AA$ of the size distribution.

the largest contribution to the microstrain. Further growth of the grains at temperatures between 1300 and $1400{ }^{\circ} \mathrm{C}$ causes the microstrain to decrease as the composition within the grains becomes more homogeneous.

\section{Mechanical properties}

Nanocomposite films consisting of an amorphous phase and one or more crystalline phases have previously been seen to exhibit very high hardness. ${ }^{1,2}$ In the as-deposited ZrAlN films, however, the hardness is low compared to other nanocomposites. The hardness of arc evaporated $\mathrm{ZrN}$ is usually found in the range between 20 and $30 \mathrm{GPa}^{45,46} \mathrm{At}$ too small grain sizes, the hardness can decrease as has been observed for $\mathrm{CrN}^{47}$ and $\mathrm{ZrN}^{48}$ This has been explained by grain boundary sliding and an increased porosity due to the large amount of grain boundaries. ${ }^{49,50}$ In this case, there is a large amount of amorphous or disordered material in the as-deposited film. Thus, in addition to an increased fraction of grain boundaries due to the small grains, the amorphous phase might exhibit a low hardness.

During annealing, the hardness increases and is at all temperatures higher than for the as-deposited film. The maximum hardness is found for the film annealed at $1250^{\circ} \mathrm{C}$. At this temperature, the fraction of $c-\mathrm{ZrN}$ grains has increased as observed from the SAXS results, see Fig. 8(b). The mean grain size is, however, not larger than after annealing in $1150{ }^{\circ} \mathrm{C}$. Thus, the maximum hardness is obtained as the film consists of small crystalline grains with a smaller amount of amorphous phase compared to the as-deposited film. For Ti-Si-N films, it has been observed that a maximum hardness is obtained when there is just enough amorphous phase to cover the crystallites. ${ }^{33}$ It was found that when the amount of amorphous phase is too large, the lower hardness of this phase caused the hardness of the films to decrease, similar to the as-deposited film here.

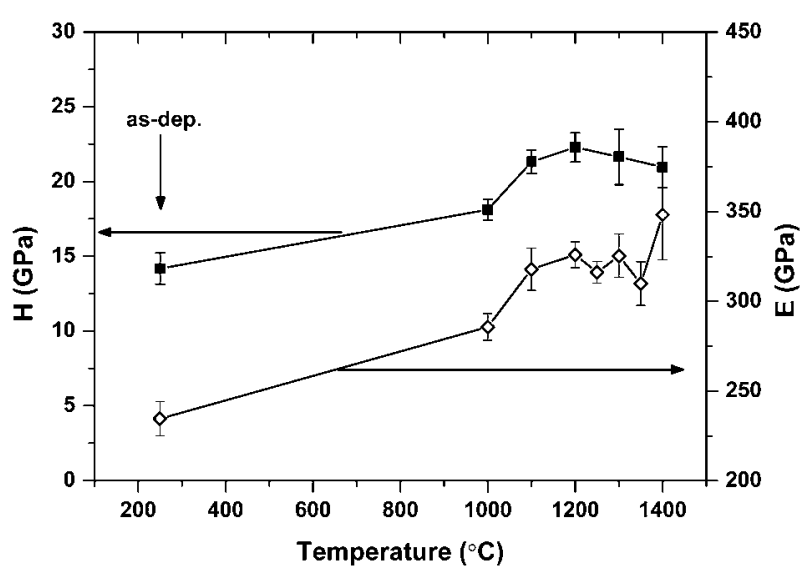

FIG. 9. Hardness and elastic modulus as a function of annealing temperature.

Annealing in temperatures higher than $1250{ }^{\circ} \mathrm{C}$ causes the hardness to decrease slightly. This is connected to growth of the $c-\mathrm{ZrN}$ grains and at $1400{ }^{\circ} \mathrm{C}$ with the formation of $h$-AlN. Similar results were obtained for the mechanical properties as a function of annealing temperature for nanocomposite $\mathrm{Ti}-\mathrm{Si}-\mathrm{C}$ thin films. ${ }^{51} \mathrm{In}$ these $\mathrm{Ti}-\mathrm{Si}-\mathrm{C}$ films, the increased fraction of crystalline $\mathrm{TiC}$ increased the hardness, while at higher annealing temperatures, the increased size of TiC grains caused the hardness to decrease.

The elastic modulus of the ZrAlN film increases with annealing temperature and reaches its maximum after annealing in $1400{ }^{\circ} \mathrm{C}$. $\mathrm{Kim}^{52}$ showed that the elastic modulus of a nanocrystalline material is dependent on both the grain size and the porosity. The increase can thus be related to both an increased grain size, decreased porosity, and decreased amount of the amorphous phase. 
This was also observed as the fraction of TiC increased and the amount of amorphous phase decreased in $\mathrm{Ti}-\mathrm{Si}-\mathrm{C}$ films. ${ }^{51}$ The value for the ZrAlN film is after annealing at $1400{ }^{\circ} \mathrm{C} 348 \mathrm{GPa}$, between the values for $c$ - $\mathrm{ZrN}$ $\left(460 \mathrm{GPa}^{53,54}\right)$ and $h$-AlN $\left(300 \mathrm{GPa}^{55,56}\right)$.

\section{CONCLUSIONS}

Nanocomposite ZrAlN thin films consisting of nanometer-sized grains of $c$ - $\mathrm{ZrN}$ and $h$-AlN embedded in an amorphous ZrAlN matrix were deposited using cathodic arc evaporation. The hardness of the as-deposited film is low due to the large amount of amorphous phase and the small crystallite size. Annealing of the film causes a phase transformation of the amorphous phase to the equilibrium phases $c$ - $\mathrm{ZrN}$ and $h$-AlN. The transformation can be divided into three steps. First, for annealing temperatures between 1100 and $1250{ }^{\circ} \mathrm{C}$, nucleation of $c$ - $\mathrm{ZrN}$ grains is dominating with additional growth of the existing $c-\mathrm{ZrN}$ grains. In the second step, between 1250 and $1400{ }^{\circ} \mathrm{C}$, growth of the $c-\mathrm{ZrN}$ grains occurs. Finally, growth of $h$-AlN grains is suppressed until a temperature of $1400{ }^{\circ} \mathrm{C}$, which is assigned to the presence of $\mathrm{Zr}$ and a large amount of $\mathrm{N}$ in the AlN-rich domains at lower temperatures. The nucleation of $c-\mathrm{ZrN}$ improves the mechanical properties of the film, and a maximum hardness is obtained, while there is a minimized amount of amorphous phase in the nanocomposite before $h$-AlN growth.

\section{ACKNOWLEDGMENTS}

The Swedish Research Council (VR) Project and Linnaeus Grants as well as the VINNEX center of Excellence on Functional Nanoscale Materials (FunMat) are acknowledged for the financial support. Dr. Naureen Ghafoor, Linköping University, assisted with TEM work with instruments provided by the KAW Foundation. The use of the Advanced Photon Source was supported by the U.S. Department of Energy, Office of Science, Office of Basic Energy Sciences under Contract No. DE-AC02$06 \mathrm{CH} 11357$.

\section{REFERENCES}

1. S. Veprek and S. Reiprich: A concept for the design of novel superhard coatings. Thin Solid Films 268(1-2), 64 (1995).

2. S. Veprek, A. Niederhofer, K. Moto, T. Bolom, H.D. Männling, P. Nesladek, G. Dollinger, and A. Bergmaier: Composition, nanostructure and origin of the ultrahardness in nc-TiN/a- $\mathrm{Si}_{3} \mathrm{~N}_{4} / \mathrm{a}-$ and nc- $\mathrm{TiSi}_{2}$ nanocomposites with $\mathrm{HV}=80$ to $\geq 105 \mathrm{GPa}$. Surf. Coat. Technol. 133-134, 152 (2000).

3. D. Ma, S. Ma, and K. Xu: Superhard nanocomposite Ti-Si-C-N coatings prepared by pulsed-d.c. plasma enhanced CVD. Surf. Coat. Technol. 200, 382 (2005).

4. Y. Guo, S. Ma, and K. Xu: Effects on carbon content and annealing temperature on the microstructure and hardness of super hard
Ti-Si-C-N nanocomposite coatings prepared by pulsed d.c. PCVD Surf. Coat. Technol. 201, 5240 (2007).

5. A. Winkelmann, J.M. Cairney, M.J. Hoffman, P.J. Martin, and A. Bendavid: Zr-Si-N films fabricated using hybrid cathodic arc and chemical vapour deposition: Structure vs. properties. Surf. Coat. Technol. 200(14-15), 4213 (2006).

6. C. Mitterer, P. Losbichler, F. Hofer, P. Warbichler, P.N. Gibson, and W. Gissler: Nanocrystalline hard coatings within the quasibinary system TiN-TiB2. Vacuum 50(3-4), 313 (1998).

7. P. Karvankova, M.G.J. Veprek-Heijman, O. Zindulka, A. Bergmaier, and S. Veprek: Superhard nc-TiN/a-BN and nc-TiN/a- $\mathrm{TiB}_{\mathrm{x}} / \mathrm{a}-\mathrm{BN}$ coatings prepared by plasma CVD and PVD: A comparative study of their properties. Surf. Coat. Technol. 163-164(0), 149 (2003).

8. H.-D. Männling, D.S. Patil, K. Moto, M. Jilek, and S. Veprek: Thermal stability of superhard nanocomposite coatings consisting of immiscible nitrides. Surf. Coat. Technol. 146-147, 263 (2001).

9. J.S. Koehler: Attempt to design a strong solid. Phys. Rev. B 2(2), 547 (1970).

10. U. Helmersson, S. Todorova, S.A. Barnett, J.E. Sundgren, L.C. Markert, and J.E. Greene: Growth of single-crystal TiN/VN strained-layer superlattices with extremely high mechanical hardness. J. Appl. Phys. 62(2), 481 (1987).

11. H. Söderberg, M. Odén, J.M. Molina-Aldareguia, and L. Hultman: Nanostructure formation during deposition of $\mathrm{TiN} / \mathrm{SiN}_{\mathrm{x}}$ nanomultilayer films by reactive dual magnetron sputtering. J. Appl. Phys. 97(11), 114327 (2005).

12. P.H. Mayrhofer, A. Hörling, L. Karlsson, C. Mitterer, and L. Hultman: Self-organized nanostructures in the Ti-Al-N system. Appl. Phys. Lett. 83(10), 2049 (2003).

13. A. Hörling, L. Hultman, M. Odén, J. Sjölén, and L. Karlsson: Mechanical properties and machining performance of $\mathrm{Ti}_{1-\mathrm{x}} \mathrm{Al}_{\mathrm{x}} \mathrm{N}$ coated cutting tools. Surf. Coat. Technol. 191(2-3), 384 (2005).

14. A. Knutsson, M.P. Johansson, P.O.Å. Persson, L. Hultman, and M. Odén: Thermal decomposition products in arc evaporated TiAlN/TiN multilayers. Appl. Phys. Lett. 93, 143110 (2008).

15. F. Tasnádi, I.A. Abrikosov, L. Rogström, J. Almer, M.P. Johansson, and M. Odén: Significant elastic anisotropy in $\mathrm{Ti}_{1-\mathrm{x}} \mathrm{Al}_{\mathrm{x}} \mathrm{N}$ alloys. Appl. Phys. Lett. 97, 231902 (2010).

16. A. Flink, J.M. Andersson, B. Alling, R. Daniel, J. Sjölén, L. Karlsson, and L. Hultman: Structure and thermal stability of arc evaporated $\left(\mathrm{Ti}_{0.33} \mathrm{Al}_{0.67}\right)_{1-\mathrm{x}} \mathrm{Si}_{\mathrm{x}} \mathrm{N}$ thin films. Thin Solid Films 517(2), 714 (2008).

17. L.J.S. Johnson, L. Rogström, M.P. Johansson, M. Odén, and L. Hultman: Microstructure evolution and age hardening in (Ti, Si)(C, N) thin films deposited by cathodic arc evaporation. Thin Solid Films 519, 1397 (2010).

18. P.H. Mayrhofer, M. Stoiber, and C. Mitterer: Age hardening of PACVD TiBN thin films. Scr. Mater. 53(2), 241 (2005).

19. H. Lind, R. Forsén, B. Alling, N. Ghafoor, F. Tasnádi, M.P. Johansson, I.A. Abrikosov, and M. Odén: Improving thermal stability of hard coating films via a concept of multicomponent alloying. Appl. Phys. Lett. 99, 091903 (2011).

20. H. Hasegawa, M. Kawate, and T. Suzuki: Effects of Al contents on microstructures of $\mathrm{Cr}_{1-\mathrm{x}} \mathrm{Al}_{\mathrm{x}} \mathrm{N}$ and $\mathrm{Zr}_{1-\mathrm{x}} \mathrm{Al}_{\mathrm{x}} \mathrm{N}$ films synthesized by cathodic arc method. Surf. Coat. Technol. 200, 2409 (2005).

21. R. Lamni, R. Sanjinés, M. Parlinska-Wojtan, A. Karimi, and F. Lévy: Microstructure and nanohardness properties of Zr-Al-N and Zr-Cr-N thin films. J. Vac. Sci. Technol., A 23(4), 593 (2005).

22. L. Rogström, L.J.S. Johnson, M.P. Johansson, M. Ahlgren, L. Hultman, and M. Odén: Age hardening in arc-evaporated ZrAlN thin films. Scr. Mater. 62, 739 (2010).

23. L. Rogström, L.J.S. Johnson, M.P. Johansson, M. Ahlgren, L. Hultman, and M. Odén: Thermal stability and mechanical properties of arc evaporated ZrN/ZrAlN multilayers. Thin Solid Films 519, 694 (2010). 
24. W.C. Oliver and G.M. Pharr: An improved technique for determining hardness and elastic modulus using load and displacement sensing indentation experiments. J. Mater. Res. 7(6), 1564 (1992).

25. J. Almer, U. Lienert, R.L. Peng, C. Schlauer, and M. Odén: Strain and texture analysis of coatings using high-energy x-rays. J. Appl. Phys. 94(1), 697 (2003).

26. M.G. Brik and C.G. Ma: First-principles studies of the electronic and elastic properties of metal nitrides $\mathrm{XN}(\mathrm{X}=\mathrm{Cs}, \mathrm{Ti}, \mathrm{V}, \mathrm{Cr}, \mathrm{Zr}$, Nb). Comp. Mat. Sci. 51, 380 (2012).

27. P.R. Jemian, J.R. Weertman, G.G. Long, and R.D. Spal: Characterization of $9 \mathrm{Cr}-1 \mathrm{MoVNb}$ steel by anomalous small-angle $\mathrm{x}$-ray scattering. Acta Metall. Mater. 39(11), 2477 (1991).

28. J. Ilavsky and P.R. Jemian: Irena: Tool suite for modeling and analysis of small-angle scattering. J. Appl. Crystallogr. 42(2), 347 (2009).

29. $\mathrm{Al}_{3} \mathrm{Zr}$, PDF No. 48-1385, JCPDS - International Centre for Diffraction Data. (1998).

30. $\mathrm{Al}_{3} \mathrm{Zr}_{4}$, PDF No. 48-1381, JCPDS - International Centre for Diffraction Data. (1998).

31. I. Petrov, P.B. Barna, L. Hultman, and J.E. Greene: Microstructural evolution during film growth. J. Vac. Sci. Technol., A 21(5), S117 (2003).

32. M. Diserens, J. Patscheider, and F. Lévy: Improving the properties of titanium nitride by incorporation of silicon. Surf. Coat. Technol. 108-109(1-3), 241 (1998).

33. J. Patscheider, T. Zehnder, and M. Diserens: Structure-performance relations in nanocomposite coatings. Surf. Coat. Technol. 146-147, 201 (2001).

34. C.S. Sandu, F. Medjani, R. Sanjinés, A. Karimi, and F. Lévy: Structure, morphology and electrical properties of sputtered $\mathrm{Zr}-\mathrm{Si}-\mathrm{N}$ thin films: From solid solution to nanocomposite. Surf. Coat. Technol. 201(7), 4219 (2006).

35. A. Anders: Cathodic Arcs, From Fractal Spots to Energetic Condensation (Springer Series, New York, NY, 2008).

36. D.S. Yee, J.J. Cuomo, M.A. Frisch, and D.P.E. Smith: Reactive radio frequency sputter deposition of higher nitrides of titanium, zirconium, and hafnium. J. Vac. Sci. Technol., A 4(3), 381 (1986).

37. A.J. Perry: On the existence of point defects in physical vapor deposited films of TiN, ZrN, and HfN. J. Vac. Sci. Technol., A 6(3), 2140 (1988).

38. J.P. Dauchot, S. Edart, M. Wautelet, and M. Hecq: Synthesis of zirconium nitride films monitored by in situ soft x-ray spectrometry. Vacuum 46(8-10), 927 (1995).

39. L. Pichon, T. Girardeau, A. Straboni, F. Lignou, P. Guérin, and J. Perrière: Zirconium nitrides deposited by dual ion beam sputtering: Physical properties and growth modelling. Appl. Surf. Sci. 150 (1-4), 115 (1999).

40. H.M. Benia, M. Guemmaz, G. Schmerber, A. Mosser, and J.-C. Parlebas: Investigations on non-stoichiometric zirconium nitrides. Appl. Surf. Sci. 200, 231 (2002).
41. H. Spillmann, P.R. Willmott, M. Morstein, and P.J. Uggowitzer: $\mathrm{ZrN}, \mathrm{Zr}_{\mathrm{x}} \mathrm{Al}_{\mathrm{y}} \mathrm{N}$ and $\mathrm{Zr}_{\mathrm{x}} \mathrm{Ga}_{\mathrm{y}} \mathrm{N}$ thin films - novel materials for hard coatings grown using pulsed laser deposition. Appl. Phys. A 73, 441 (2001).

42. J.-L. Ruan, J.-L. Huang, J.S. Chen, and D.-F. Lii: Effects of substrate bias on the reactive sputtered $\mathrm{Zr}-\mathrm{Al}-\mathrm{N}$ diffusion barrier films. Surf. Coat. Technol. 200, 1652 (2005).

43. L.E. Toth: Transition Metal Carbides and Nitrides (Academic Press, New York, 1971).

44. B. Uhrenius: Evaluation of molar volumes in the Co-W-C system and calculation of volume fractions of phases in cemented carbides. Int. J. Refract. Met. Hard Mater. 12, 121 (1994).

45. K.A. Gruss, T. Zheleva, R.F. Davis, and T.R. Watkins: Characterization of zirconium nitride coatings deposited by cathodic arc sputtering. Surf. Coat. Technol. 107, 115 (1998).

46. E.W. Niu, L. Li, G.H. Lv, H. Chen, W.R. Feng, S.H. Fan, S.Z. Yang, and X.Z. Yang: Influence of substrate bias on the structure and properties of $\mathrm{ZrN}$ films deposited by cathodic vacuum arc. Mater. Sci. Eng., A 460-461, 135 (2007).

47. P.H. Mayrhofer, G. Tischler, and C. Mitterer: Microstructure and mechanical/thermal properties of $\mathrm{Cr}-\mathrm{N}$ coatings deposited by reactive unbalanced magnetron sputtering. Surf. Coat. Technol. 142-144, 78 (2001).

48. H.-M. Tung, J.-H. Huang, D.-G. Tsai, C.-F. Ai, and G.-P. Yu: Hardness and residual stress in nanocrystalline $\mathrm{ZrN}$ films: Effect of bias voltage and heat treatment. Mater. Sci. Eng., A 500(1-2), 104 (2009).

49. R.W. Siegel and G.E. Fougere: Mechanical properties of nanophase metals. Nanostruct. Mater. 6(1-4), 205 (1995).

50. J. Schiotz, F.D. Di Tolla, and K.W. Jacobsen: Softening of nanocrystalline metals at very small grain sizes. Nature 391(6667), 561 (1998).

51. M. Rester, J. Neidhardt, P. Eklund, J. Emmerlich, H. Ljungcrantz, L. Hultman, and C. Mitterer: Annealing studies of nanocomposite Ti-Si-C thin films with respect to phase stability and tribological performance. Mater. Sci. Eng., A 429(1-2), 90 (2006).

52. H.S. Kim and M.B. Bush: The effects of grain size and porosity on the elastic modulus of nanocrystalline materials. Nanostruct. Mater. 11(3), 361 (1999).

53. E. Török, A.J. Perry, L. Chollet, and W.D. Sproul: Young's modulus of TiN, TiC, ZrN and HfN. Thin Solid Films 153(1-3), 37 (1987).

54. A.J. Perry: A contribution to the study of Poisson's ratios and elastic constants of TiN, ZrN and HfN. Thin Solid Films 193/194, 463 (1990).

55. D. Gerlich, S.L. Dole, and G.A. Slack: Elastic properties of aluminium nitride. J. Phys. Chem. Solids 47(5), 437 (1986).

56. V. Mortet, M. Nesladek, K. Haenen, A. Morel, M. D'Olieslaeger, and M. Vanecek: Physical properties of polycrystalline aluminium nitride films deposited by magnetron sputtering. Diamond Relat. Mater. 13 (4-8), 1120 (2004). 